\title{
The role of norepinephrine in the expression of learned olfactory neurobehavioral responses in infant rats
}

\author{
R. M. SULLIVAN and D. A. WILSON \\ University of Oklahoma, Norman, Oklahoma
}

\begin{abstract}
In neonatal rats, norepinephrine (NE) is necessary and sufficient for the acquisition of an olfactory preference and its associated olfactory bulb neural modifications as assessed by $\left[{ }^{14} \mathrm{C}\right] 2$ deoxyglucose (2-DG) and electrophysiology. In the present studies, we assessed the influence of $\mathrm{NE}$ on the expression of a conditioned odor preference and its associated olfactory bulb neural modifications in neonatal rats. On Postnatal Day 5 (PN 5), pups were trained to prefer an odor in a 1-h classical conditioning paradigm. Experimental paired odor-stroke pups received 20 forward pairings of a 10-sec peppermint odor and a 9-sec reinforcing tactile stimulation (stroking). Control pups received either random stroke-odor pairings or were naive (received neither the odor nor stroking). The next day (PN 6), the pups were injected with either an NE $\beta$-receptor antagonist, (propranolol or timolol) or saline, $1 \mathrm{~h}$ prior to testing. The pups were tested for a behavioral olfactory preference and assessed for differential olfactory bulb activity with $\left[{ }^{14} \mathrm{C}\right] 2$-DG autoradiography. The results indicate that $\mathrm{NE}$ is not necessary for the expression of the learned neurobehavioral response.
\end{abstract}

Development and plasticity in central sensory pathways can be modulated by norepinephrine (NE). For example, in both mature and immature sensory systems, NE appears to be critical for experience-dependent changes in functional organization of the visual (Kasamatsu \& Pettigrew, 1976; Singer, Tretter, \& Yinon, 1982) and olfactory systems (Gervais, Holley, \& Keverne, 1988; Gray, Freeman, \& Skinner, 1986; Rosser \& Keverne, 1985; Sullivan, McGaugh, \& Leon, 1991; Sullivan, Wilson, \& Leon, 1989). However, although NE is critical for the induction of experience-dependent changes, in most cases the expression and maintenance of those changes are not NE-dependent (Bliss, Goddard, \& Riives, 1983; Kasamatsu \& Pettigrew, 1976; Rosser \& Keverne, 1985).

The developing olfactory system is a particularly attractive model system with which to explore further the role of $\mathrm{NE}$ in the acquisition and expression of neurobehavioral plasticity. In the rat olfactory bulb, NE is present (Brunjes, Smith-Crafts, \& McCarty, 1985; McLean \& Shipley, 1991) and functional (Wilson \& Leon, 1988) during the 1 st postnatal week. Furthermore, NE has been shown to be necessary for acquisition of both associatively conditioned behavioral olfactory preferences and correlated modified olfactory bulb neural responses to the condi-

This research was supported by NIDCD Grant DC00480 to R. M. Sullivan and NSF Grant BNS-8819189 to D. A. Wilson. The authors would like to thank David Zyzak, Rebecca Smart, Tammy Thomas, and John Nalagen for assistance in data collection and analysis. Correspondence should be addressed to Regina M. Sullivan, Developmental Psychology Laboratory, Department of Psychology, University of Oklahoma, Norman, OK 73019. tioned odor in newborns (Sullivan et al., 1991; Sullivan et al., 1989). Blockade of NE $\beta$-receptors via either systemic injections (Sullivan et al., 1989) or intrabulbar infusions (Lin, Sullivan, \& Wilson, 1990) during associative conditioning in infant rats disrupts acquisition of learned neurobehavioral responses in a dose-dependent manner. In fact, recent evidence suggests that NE antagonists block a specific component of the olfactory bulb neurophysiological response to reward (Wilson \& Sullivan, in press), perhaps thereby preventing neural/synaptic modifications required for acquisition.

The present experiment was an investigation of the role of NE in the expression of learned responses following preweanling olfactory conditioning. The results suggest that NE is not required for retrieval and expression of previously learned olfactory neurobehavioral responses in newborns.

\section{METHOD}

\section{Subjects}

The subjects were 213 male and female Postnatal Day 6 (PN 6) rat pups from 15 different litters (9-10 pups/group for behavior tests; 6-7 pups/group for 2-deoxyglucose [2-DG] tests) born of Wistar rats (offspring of Hilltop Lab Animals, Scottdale, PA) in the vivarium at the University of Oklahoma. No more than 1 male and 1 female pup from a given litter was used in an experimental condition. Dams were housed in rectangular polypropylene cages $(34 \times 29 \times 17 \mathrm{~cm})$ lined with wood chips in a temperature- $\left(23^{\circ} \mathrm{C}\right)$ and light- (7:00 a.m.-7:00 p.m.) controlled room. Ad-lib food and water were available at all times. Births were checked at 8:00 a.m. and 5:00 p.m. Litters were culled to 12 pups on the day after birth (PN 1). The day of birth was considered to be PN 0 . All conditioning and testing were performed during the light phase of the light:dark cycle. 


\section{Classical Conditioning}

On PN 5, pups were removed from the litter and randomly assigned to a training condition. During the $1-\mathrm{h}$ training session, pups received 20 presentations of the 10 -sec olfactory conditioned stimulus (CS) and reinforcing unconditioned stimulus (US) with an intertrial interval (ITI) of $3 \mathrm{~min}$. The conditioning groups were: (1) paired odor-stroke-pups received 20 pairings of a 10 -sec peppermint odor while being vigorously stroked with a sable hair brush on all body areas during the last $9 \mathrm{sec}$; (2) random stroke-odorpups received 20 odor presentations with a $3-\mathrm{min}$ ITI, while the stroking was randomly presented once during each ITI; and (3) naive--pups received neither of the stimuli. The tactile stimulation produced by stroking was used to mimic maternal stimulation and has reinforcing properties in infant rats as robust as intraoral infusion of milk (Sullivan \& Hall, 1988). The odor was peppermint extract (Schilling, Baltimore, MD) presented in a $1: 10$ dilution at $2 \mathrm{l} / \mathrm{min}$ with a flow-dilution olfactometer. Pups remained with the dam until $10 \mathrm{~min}$ prior to training, at which time they were placed in individual 1,000-ml glass cylinders. Following a 10-min adaptation period in which pups recovered from experimental handling, training began. Following training, the pups were returned to the dam for $24 \mathrm{~h}$.

\section{Behavioral Testing and Drugs}

On PN 6,60 min prior to the odor preference test, the pups were injected with (Caza, 1984; Sullivan et al., 1989) DL-propranolol $(10,20$, or $40 \mathrm{mg} / \mathrm{kg}$, i.p.), timolol (3.0 mg/kg s.c., a dose providing potency comparable to the $20 \mathrm{mg} / \mathrm{kg}$ dose of propranolol without the anesthetic properties of propranolol; Goodman \& Gilman, 1985; Sullivan et al., 1989), or saline (volume of $5 \mathrm{cc} / \mathrm{kg}$ ). The pups were returned to the dam $5 \mathrm{~min}$ following the injection and remained with her for $55 \mathrm{~min}$. Pups were then given a two-odor choice test to assess the expression of an odor preference (Cornwell-Jones \& Sobrian, 1977). The test consisted of a two-odor choice between the conditioned peppermint odor and a familiar pine odor. The test apparatus was an opaque Plexiglas box $(40 \times 21 \times 15 \mathrm{~cm})$ with a small grid wire-mesh $(1 \times 1 \mathrm{~cm})$ floor divided in half by a $2-\mathrm{cm}$ wide "neutral zone," which ran the length of the box. Two trays $(20 \times 20 \times 5 \mathrm{~cm})$, each containing $500 \mathrm{ml}$ of pine shavings, were placed beneath each half of the wire-mesh floor. One tray had pine shavings scented with $1 \mathrm{ml}$ of peppermint extract, and the other was filled with plain pine shavings. A 1-min trial test began when the pup was placed in the neutral zone. When the pup's head and forepaws crossed from the neutral zone into either half of the test box, the experimenter started recording the time. At the end of the test, the total time the pup spent over each of the two odors was recorded by a microcomputer. Each pup was tested for five trials, and between the 1-min trials, the pup was taken out of the test box. The direction in which the pups were placed into the box was counterbalanced across trials. Data were collected blind with respect to drug and conditioning group.

\section{2-DG Autoradiography and Drugs}

On PN 6,60 min prior to the 2-DG test, the pups were injected with either DL-propranolol $(20 \mathrm{mg} / \mathrm{kg}$ in physiological saline, a dose capable of blocking acquisition of this neonatal neurobehavioral response) or vehicle.

For the 2-DG test, the pups were injected with ${ }^{14} \mathrm{C} 2-\mathrm{DG}$ $(20 \mu \mathrm{Ci} / 100 \mathrm{~g})$ immediately prior to odor delivery and placed in a glass test canister $(20 \times 10 \mathrm{~cm})$. Odor was delivered at a flow rate of $2 \mathrm{l} / \mathrm{min}$ and a concentration of 1:10 of saturated vapor.

Following odor exposure, the pups were decapitated and their brains were quickly removed and frozen in methylbutane at $-40^{\circ} \mathrm{C}$. The frozen brain was equilibrated to $-17^{\circ} \mathrm{C}$ in a cryostat for $45 \mathrm{~min}$ and cut coronally in $20-\mu \mathrm{m}$ sections. Each section was immediately picked up on a cover slip and placed on a slide warmer at $60^{\circ} \mathrm{C}$ for 5-10 min. Coverslips were glued to a sheet of cardboard and exposed to Kodak SB-5 X-ray film for 7 days at $22^{\circ} \mathrm{C}$ in an exposure cassette. A set of ${ }^{14} \mathrm{C}$ labeled methylmethacrylate standards (American Radiolabeled Chemicals), previously calibrated to ${ }^{14} \mathrm{C}$ uptake in $20-\mu \mathrm{m}$ brain sections, was exposed with each sheet of film. Autoradiographs were developed according to standard techniques.

\section{Autoradiograph Analysis}

The autoradiographs were analyzed with a computer-based digital image processor (MCID; Imaging Research, Inc.) that allowed pseudocolor imaging and quantitative optical densitometry. To quantify 2-DG uptake, the computer constructed a calibration curve that related the gray values of ${ }^{14} \mathrm{C}$ standards that were exposed with the brain sections to those of their previously determined ${ }^{14} \mathrm{C}$ tissue equivalent. The computer then translated the density measures into ${ }^{14} \mathrm{C}$ levels, and hence 2-DG uptake by the tissue.

Measurements of 2-DG uptake were taken in three areas of the olfactory bulb: (1) the periventricular core, which has a relatively stable level of 2-DG uptake across conditioning treatments; (2) focal areas of the glomerular layer demonstrating odor-specific patterns of 2-DG uptake-odor presentation during 2-DG uptake produces an odor-specific spatial pattern of 2-DG uptake in the olfactory bulb glomerular layer, regardless of the animal's previous experience with that odor (Coopersmith \& Leon, 1984; Jourdan, Duveau, Astic, \& Holley, 1980; Sharp, Kauer, \& Shepherd, 1975); density of uptake within these focal areas, however, varies with previous experience of that odor (Coopersmith \& Leon, 1984; Sullivan \& Leon, 1986; Sullivan \& Wilson, 1991); and (3) areas of the glomerular layer that did not exhibit an odor-specific pattern of 2-DG uptake.

\section{RESULTS}

Blockade of NE $\beta$-receptors with either propranolol (Figure 1) or timolol (Figure 2) during testing did not appear to influence the expression of a learned olfactorybased behavior in neonatal rats. Propranolol was ineffective at all doses tested. A $3 \times 4$ analysis of variance (ANOVA) yielded a nonsignificant drug effect and a significant training effect $[F(2,108)=63.3, p<.001]$. Post hoc analysis (Tukey, $p<.05$ ) revealed that the paired odor-stroke saline group was not significantly different from any of the paired odor-stroke propranolol groups. However, both the paired odor-stroke saline group and the paired odor-stroke propranolol groups were significantly different from the control groups.

As is illustrated in Figure 2, timolol was similarly without effect. A $2 \times 3$ ANOVA yielded a nonsignificant drug effect and a significant effect for training $[F(2,48)=10.7, p<.001]$. Post hoc tests (Tukey, $p<.05$ ) revealed that paired odor-stroke saline pups did not significantly differ from pups in the paired odor-stroke timolol group. Moreover, each of these groups spent significantly more time over the peppermint odor than did the control random odor-stroke and naive groups.

As is illustrated in Figure 3, propranolol did not block the expression of the olfactory bulb neural changes that are associated with olfactory preferences. A $2 \times 3$ ANOVA yielded a significant training effect $[F(2,34)=$ $8.8, p<.01]$; there was no significant drug $\times$ training interaction. Post hoc tests (Fisher, $p<.01$ ) revealed that pups in the paired odor-stroke saline group differed significantly from pups in the saline control groups. Simi- 


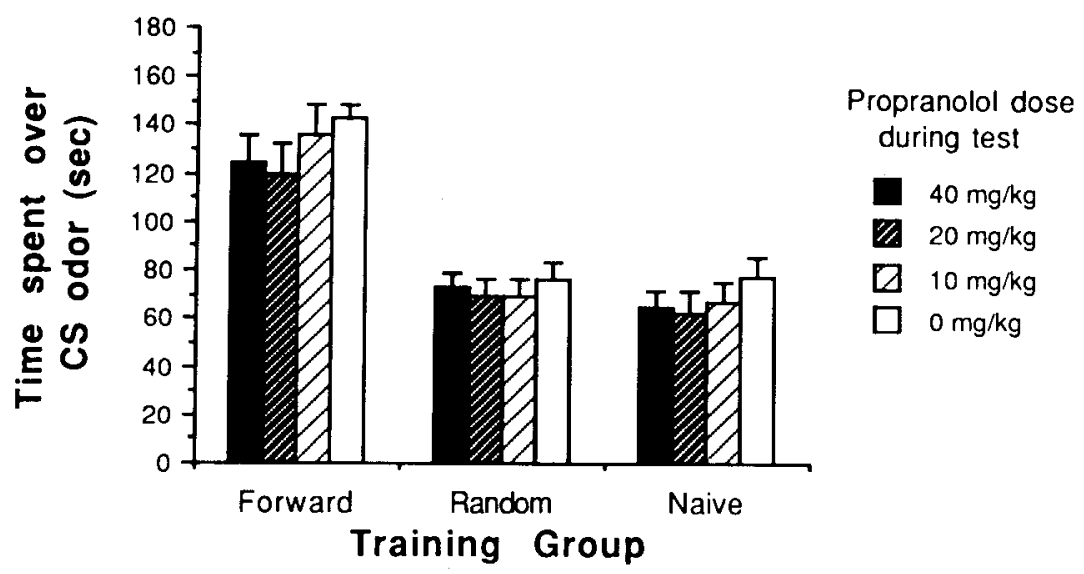

Figure 1. Mean time ( $\pm S E$ ) spent over peppermint odor conditioned stimulus (CS) in the two-odor choice test as a function of training condition: experimental group = paired; control groups $=$ random or naive. During testing, pups were under the influence of either propranolol, an NE $\beta$-receptor antagonist, or saline. We have previously demonstrated that the $20-\mathrm{mg} / \mathrm{kg}$ dose is sufficient to block acquisition of olfactory preferences in newborns (Sullivan, McGaugh, \& Leon, 1991).

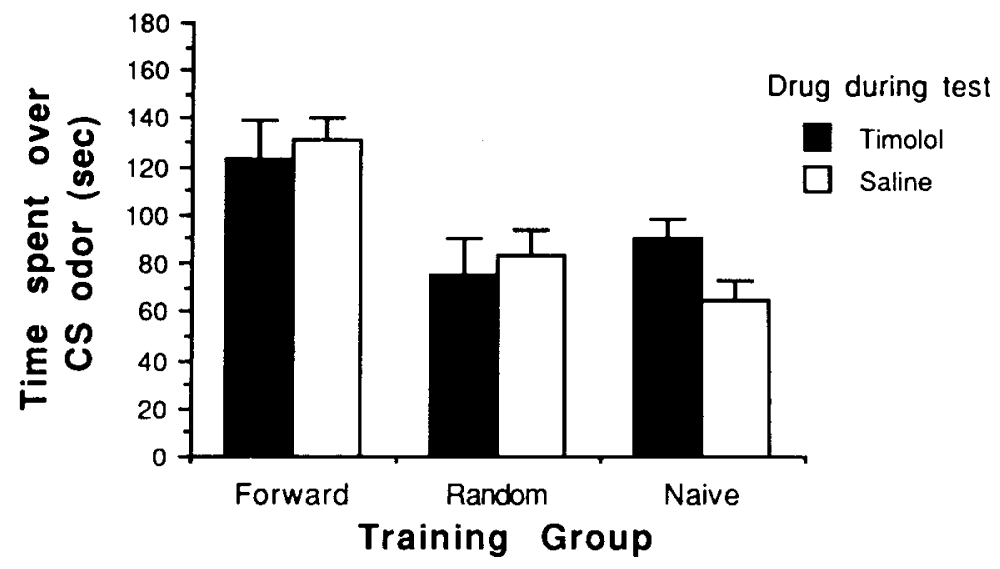

Figure 2. Mean time ( $\pm S E$ ) spent over peppermint odor conditioned stimulus (CS) in the two-odor choice test as a function of training condition: experimental group = paired; control groups $=$ random or naive. During testing, pups were under the influence of either timolol, an NE $\beta$-receptor antagonist, or saline.

larly, the paired odor-stroke propranolol pups differed significantly from pups in the propranolol control groups. Focal 2-DG uptake levels were 30\%-33\% higher for paired odor-stroke saline pups than for saline controls and 26\%-31\% higher for paired odor stroke propranolol pups than for propranolol controls. Thus, both saline and propranolol paired odor-stroke pups had enhanced 2-DG uptake, relative to their respective drug control groups.

The enhanced 2-DG uptake in propranolol paired odor-stroke pups, however, was relative to a reduced overall 2-DG uptake in propranolol pups. All pups injected with propranolol during testing had significantly lower 2-DG uptake within their olfactory bulbs than did pups injected with saline. A $2 \times 3$ ANOVA yielded a significant drug effect $[F(1,34)=9.8, p<.05]$. Post hoc
Fisher analysis $(p<.05)$ showed that paired odor-stroke propranolol and random odor-stroke propranolol were significantly different from their saline controls; although naive propranolol pups had reduced 2-DG uptake compared to that of their saline controls, the difference did not quite reach statistical significance (Figure 3).

\section{DISCUSSION}

The present results suggest that NE is not required for the expression of learned neurobehavioral responses in infant rats. Thus, despite the reduction in NE activity, the pups were able to discriminate between the two odors in the odor preference test, access the memory for the learned odor, and express an odor preference. The in- 


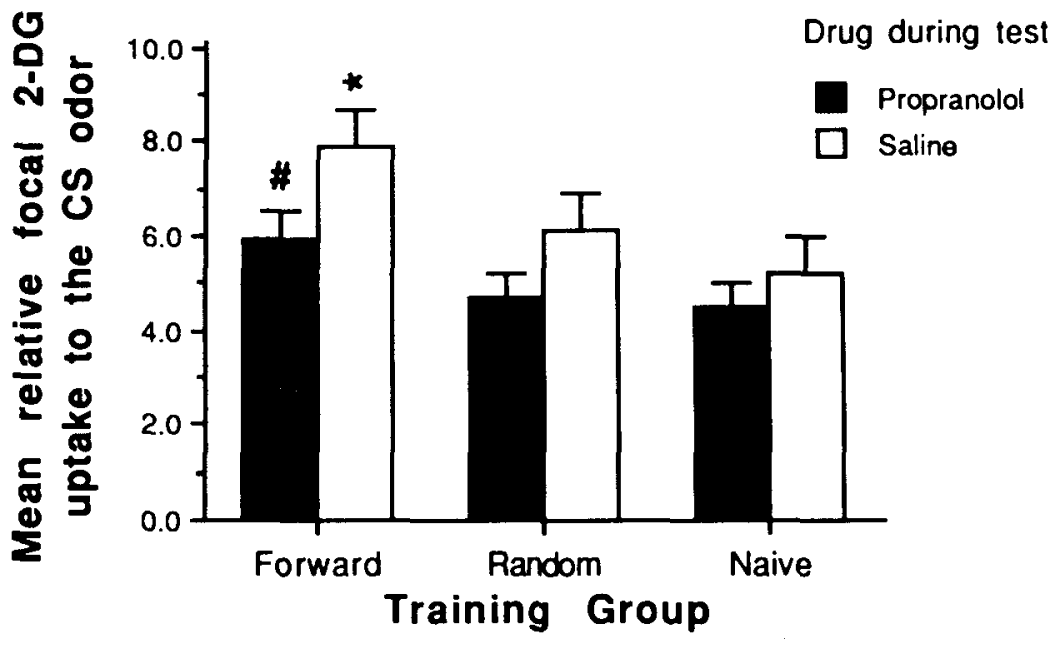

Figure 3. Mean relative 2-DG uptake $( \pm S E)$ in the spatially odor-specific focal areas of the olfactory bulb during test exposure to peppermint odor with propranolol or saline. Pups had previously been trained in the paired odor-stroke, random odor-stroke, or naive training conditions. While propranolol lowered relative uptake in all groups, focal uptake was significantly enhanced in paired animals $(p<.05)$ in both soline (*) and propranolol (\#) animals compared to the appropriate drug controls.

ability of NE to alter the expression of a learned response is in sharp contrast to the critical role of NE in the acquisition of early olfactory memories (Sullivan et al., 1991; Sullivan et al., 1989).

Similarly to the behavioral response, the modified olfactory-bulb response to the learned odor was expressed during NE receptor blockade. Overall bulb activity and responsiveness to odors, however, was reduced by propranolol. Thus, although focal 2-DG uptake in paired odor-stroke propranolol pups was less than in paired odor-stroke saline pups (Figure 3), the paired odor-stroke propranolol pups had enhanced focal 2-DG uptake relative to the other propranolol-treated pups. This decrease in baseline activity may be explained by the enhanced granule-cell-mediated inhibition that propranolol produces in the bulb (Jahr \& Nicoll, 1982; Wilson \& Leon, 1988). Despite the overall suppression, however, olfactory bulbs of conditioned animals had an enhanced response to the learned odor compared to the responses of the appropriate drug control group.

These results are similar to those reported from other laboratories. In mature female mice, NE is necessary for acquiring olfactory memories associated with mating, but it is not required for recalling/retrieving those memories (Rosser \& Keverne, 1985). In addition, in adult rats, lesions of the NE system affect acquisition of a learned behavioral/physiological response but not its performance (Cole \& Robbins, 1987).

However, other researchers have found an effect of NE depletion on performance of a learned response (Tsaltas, Gray, \& Fillenz, 1984). Moreover, NE depletion has been found to modulate expression of a learned response under certain conditions. Specifically, following NE depletion, extinction of a learned response is retarded (Cole
\& Robbins, 1987; Cornwell-Jones, Stephens, \& Dunston, 1982). These data suggest that the role of NE in the performance of learned responses may be dependent on the precise testing conditions.

In addition, these results strengthen the hypothesis (Brennan, Kaba, \& Keverne, 1990; Wilson \& Sullivan, 1990) that olfactory learning modifies bulb circuitry in a manner similar to long-term potentiation (LTP). In the hippocampus, NE modulates induction of LTP, but it is not involved in the expression of LTP once it has been induced (Bliss et al., 1983). In early olfactory learning, once the neurobehavioral changes have occurred (in the presence of NE), NE is no longer required for the expression of these learned responses.

\section{REFERENCES}

Buiss, T. V. P., Goddard, G. V., Ritves, M. (1983). Reduction of long-term potentiation in the dentate gyrus of the rat following selective depletion of monoamines. Journal of Physiology, 334, 474-491.

Brennan, P., KabA, H., Keverne, E. B. (1990). Olfactory recognition: A simple memory system. Science, 250, 1223-1226.

Brunjes, P. C., Smith-Crafts, L. K., MCCarty, R. (1985). Unilateral odor deprivation: Effects on the development of olfactory bulb catecholamines and behavior. Developmental Brain Research, 22, 1-6.

CAZA, P. C. (1984). Noradrenergic influences on blocking: Interactions with development. Physiology \& Behavior, 21, 9-17.

Cole, B. J., Robrins, T. W. (1987). Dissociable effects of lesions to the dorsal or ventral noradrenergic bundle on the acquisition, performance, and extinction of aversive conditioning. Behavioral Neuroscience, 101, 476-488.

Coopersmith, R., LeON, M. (1984). Enhanced neural response to familiar olfactory cues. Science, 225, 849-851.

Cornwell-Jones, C., Sobrian, S. K. (1977). Development of odorguided behavior in Wistar and Sprague-Dawley rat pups. Physiology \& Behavior, 19, 685-688.

Cornwell-Jones, C. A., Stephens, S. E., Dunston, G. A. (1982). 
Early odor preferences of rats are preserved by neonatal 6hydroxydopamine. Behavioral Neuroscience, 95, 217-230.

Gervais, R., Holley, A., Ke Keverne, E. B. (1988). The importance of central noradrenergic influences on the olfactory bulb in the processing of learned olfactory cues. Chemical Senses, 13, 3-12.

Goodman, L. S., Gilman, A. G. (1985). The pharmacological basis of therapeutics. New York: Macmillan.

Gray, C. M., Freeman, W. J., Skinner, J. E. (1986). Chemical dependencies of learning in the rabbit olfactory bulb: Acquisition of the transient spatial pattern change depends on norepinephrine. Behavioral Neuroscience, 100, 585-596.

JAHR, C. E., NICOLL, R. A. (1982). Noradrenergic modulation of dendro-dendritic inhibition in the olfactory bulb. Nature, 297, 227-229.

Jourdan, R., Duveau, A., Astic, L., Holley, A. (1980). Spatial distribution of [14C]-2-deoxyglucose uptake in the olfactory bulbs of rats stimulated with two different odours. Brain Research, 188, 139-154.

Kasamatsu, T., \& Petrigrew, J. D. (1976). Depletion of brain catecholamines: Failure of ocular dominance shift after monocular occlusion in kittens. Science, 194, 206-209.

Lin, W., Sullivan, R. M., Wilson, D. A. (1990). Olfactory bulb norepinephrine may be required for early olfactory learning. Society for Neuroscience Abstracts, 16, 1276.

McLean, J. H., \& SHIPLeY, M. T. (1991). Postnatal development of the noradrenergic projection from locus coeruleus to the olfactory bulb in the rat. Journal of Comparative Neurology, 304, 467-477.

Rosser, A. E., \& KeVERne, E. B. (1985). The importance of central noradrenergic neurones in the formation of an olfactory memory in the prevention of pregnancy block. Neuroscience, 15, 1141-1148.

Sharp, F., KaUer, J., ShePherd, G. M. (1975). Local sites of activity related glucose metabolism in rat olfactory bulb during olfactory stimulation. Brain Research, 263, 97-103.

Singer, W., Tretter, F., \& YinON, U. (1982). Central gating of developmental plasticity in kitten visual cortex. Journal of Physiology, 324, 221-237.
Suluivan, R. M., \& Hall, W. G. (1988). Reinforcers in infancy: Classical conditioning using stroking or intra-oral infusions of milk as a UCS. Developmental Psychobiology, 21, 215-223.

Suluvan, R. M., \& LeON, M. (1986). Early olfactory learning induces an enhanced olfactory bulb response in young rats. Developmental Brain Research, 27, 278-282.

Suluivan, R. M., \& LEON, M. (1987). One-trial olfactory learning enhances olfactory bulb responses to an appetitive conditioned odor in 7-day-old rats. Developmental Brain Research, 35, 301-311.

Suluvan, R. M., McGaugh, J., \& LeON, M. (1991). Norepinephrineinduced plasticity and one-trial olfactory learning in neonatal rats. Developmental Brain Research, 60, 219-228.

Sullivan, R. M., \& Wilson, D. A. (1991). Neural correlates of conditioned odor avoidance in infant rats. Behavioral Neuroscience, 105 , $85-90$.

Sullivan, R. M., Wilson, D. A., \& Leon, M. (1989). Norepinephrine and learning-induced plasticity in infant rat olfactory system. Journal of Neuroscience, 9, 3998-4006.

Tsaltas, E., Gray, J. A., \& Fillenz, M. (1984). Alleviation of response suppression to conditioned aversive stimuli by lesions of the dorsal noradrenergic bundle. Behavioral \& Brain Research, 13, 115-127.

WILSON, D. A., LEON, M. (1988). Noradrenergic modulation of olfactory bulb excitability in the postnatal rat. Developmental Brain Research, 42, 69-75.

WILson, D. A., \& Sullivan, R. M. (in press). Olfactory associative conditioning in infant rats with brain stimulation as reward: II. Norepinephrine mediates a specific component of the bulb response to reward. Behavioral Neuroscience.

Wilson, D. A., \& Sullivan, R. M. (1990). Olfactory associative conditioning in infant rats with brain stimulation as reward: I. Neurobehavioral consequences. Developmental Brain Research, 53, 215-221.

(Manuscript received February 1, 1991; revision accepted for publication June 10, 1991.) 